\title{
The Writer as Translator: Self-Translation in O. V. Vijayan's The Legends of Khasak
}

\section{SANJU THOMAS}

It is observed that creativity is all about negotiating through subjective experiences and transcending them to make a crucial connect with the readers. The process of translation follows the same route. This would involve a lot of enterprise especially since she is constricted by the existing framework of the source text. Other than linguistic experiments, a translator, if he/she wills, can subtly modify or brazenly rewrite a text in agreement with her ideology and context. But what happens when a writer translates his/her own work? Even when the question of accountability to the writer does not plague the self-translator, self-translation many times ends up as some kind of rewriting of the existing text. But does self-translation by default mean rewriting? In my paper I would analyse the first chapter of The Legends of Khasak, the English translation of O. V. Vijayan's phenomenal Malayalam novel Khasakkinte Ithihasam by the writer himself. A close reading of the text would reveal that there are many subtle changes Vijayan has brought in the translation. What does this do to the text and what does this say about the writer as his own translator? This analytical paper would attempt to answer these questions and thus comment on the process and politics of self-translation as rewriting.

Keywords: self-translation, Malayalam novel, O. V. Vijayan, The Legends of Khasak.

\section{Introduction}

Translation has long ceased to be a mere linguistic transfer and has come to mean a more complex and creative bridge building process between diverse cultures. The long standing criticism about the process of translation being mechanical and being inferior to creative writing has been settled to a great extend with the arrival of translators who are more aware about the process and politics of translation. Scholars of translation now have moved on to discuss about the role of translators as empowering agents and the ethics of their choices. Thus many other aspects of translation are being pondered upon that have hitherto not been paid proper attention. Self-translation is one such dimension. This paper would analyse the process of self-translation through a discussion of the intention of the writer-translators in undertaking such an exercise and proposes to look into the many different ways self-translation unfolds, many times as rewriting. This will be made clear through a close 
reading of the first chapter of O. V. Vijayan's The Legends of Khasak (1994) his own translation of the Malayalam novel Khasakkinte Ithihaasam (1969).

\section{Why Self-translation?}

The process of translation itself is many layered, and self translation makes it all the more complicated. The trepidation about being answerable to the author will not mar the creativity of the self translator as he can, in principle, take any amount of liberty with his own text. For many self translators the process of translation is a chance to rewrite the original text. Two great examples of self translators who have ended up rewriting their own works in another language are Samuel Beckett and Rabindranath Tagore, both Nobel prize winners. In Alan Friedman's 1987 collection "Beckett Translating/Translating Beckett" and Brian Fitch's 1988 monograph "Beckett and Babel" Fitch concludes that there is "one work" but two texts to deal with: "it is obviously desirable to allow for the possibility that no satisfactory synthesis of the two Beckettian texts is, in the final analysis, feasible". He points out that Beckett has taken great liberties not just at "lexical and grammatical level" but also at the "textual and discursive level" (quoted in Butler 115). Sujit Mukherjee traces the growth of a reluctant Rabindranath who believed that translating his poems into English would be like "disrobing Draupadi in court" (2009: 115) into the confident, renowned 'English' poet Tagore. The conscious liberty Tagore took with his own work could not have been done by anyone else. He quotes Tagore:

My right with regard to my own work is not of an adventitious sort. Had it been otherwise than inherent, I would have, unlike what I do, to account for each word I use. I intend to carry the essential substance of my poetry in the English translation, and this means a wide divergence from the original (2009: 119).

Mukherjee also writes about the "growing uneasiness" Tagore had in his later years about his own translations and regretted his "incompetence" and "carelessness". He felt that "languages are jealous sovereigns, and passports are rarely allowed for travelers to cross their strictly guarded boundaries" (2009: 120).

This, however, is not the case with many other bilingual writers who can handle two languages with elan. For example, Sarang mentions three poems of Arun Kolatkar — "The Hag", "Irani Restaurant" and "Three Cups of Tea" — which were included in an anthology edited by Dilip Chitre as "English versions by the poet" while the same poems when published in a special issue of Quest did not mention that they were written in Marathi first. This issue had showcased the best of Indo-Anglian poetry. Tagore too was considered an English poet in the West since nowhere did it get mentioned that the Gitanjali was translated from the Bangla. In fact after widespread criticism recently scholars have been re-assessing contribution of Tagore to the field of world literature, and how his poetry was a welcome change from the kind of poetry 
written in English during his time. The prose-poetry that he created had "Biblical overtones and was easily translatable to other languages" (Bassnett 2013:16). Ayyappa Paniker, the renowned Malayalam poet and academic is also the translator of his own poems. Dilip Chitre is another poet who has experimented with both English and Marathi (Sarang 1981: 35). V. K. N. the celebrated Malayalam writer, known for his deeply rooted analogies and experimental puns, translated many of his stories into English. Thus, one would understand that self-translation is not a marginal activity at least in the Indian context.

Why does a self-translator choose to do this activity and how does s/he do it are interesting questions that might yield different answers. Aranda writes about "Rosario Ferré, whose novels are published in both Spanish and English as if they were originals, has declared that she writes in English and then translates into Spanish to "correct mistakes" (2009: 31). This obviously is not the reason for all writers to turn self-translators. A writer, who is sometimes forced to live in another country for a considerably long time because of adverse conditions in his own nation, might start writing in the new language. Another reason could be the dissatisfaction of previous translations done by others and the faith that only the writer would be able to do justice to the translation. Many times a writer translates his/her own work after an interval of some years as in the case of O. V. Vijayan. O. V. Vijayan's Khasakkinte Ithihasam (1969) has been termed a pathbreaking novel, so much so that Malayalam literature is divided into pre and postKhasak phases. The work heralded postmodernism in Malayalam literature, ${ }^{1}$ and it delves deep into the question of identity. The novel opened a new world of possibilities where reality and myth merged, where the individual became the universal and the sinner and the saint became one (Satchidanandan 2013). The novel published in 1969 is in its 30th edition, and is still considered to be one of the most important novels in Malayalam. O. V. Vijayan translated Khasak as The Legends of Khasak into English in 1994 almost 25 years later.

In such cases the worldview and the intensity of experience of the author might have changed which allows him to look at the text from a distance. But this might result in rewriting of the text to suit his new perspective. There are others who simultaneously translate a text into another language as they write it in their mother tongue. Ayyappa Paniker is said to have done his translations this way. Here the distinction between the original and the translation gets blurred to a great extent. But considering that the creative energy of a translation is increasingly appreciated lately and that the absoluteness of the source text is something that is considered to be nonexistent, self-translation should be considered as creative translation. But it is

\footnotetext{
${ }^{1}$ The term 'athyadhunikam' (ultramodernism, high modernism) was used to qualify the novel since the term 'utharadhunikam' (postmodernism) was not in vogue in literary circles. (as mentioned in "Nation and Nationality; Concepts of Modernity and Nation in Malyalam Literature" by Manu Sudhakar Kurup).
} 
then also true that in a multilingual country like India where almost every educated Indian can speak at least two languages self-translation many times becomes rewriting. A classic example is the self-translation of Qurratulain Hyder's Aag ka Dariya (1953). M. Asaduddin in his article "Lost/Found in Translation: Qurratulain Hyder as Self-translator" details the many liberties taken by the author-translator so much so that the novel almost became a new text in translation. According to him, "the two texts cannot be substituted for one another. They remain complementary despite belonging to their own fictive universes" (2008: 248). O. V. Vijayan's translation The Legends of Khasak of his original Malayalam masterpiece can be considered one such novel.

\section{Self-translation as Rewriting the Self in The Legends of Khasak}

P. P. Raveendran in his essay "Mapping the Khasak Landscape: An Essay on Translation" (2009) analyses the translation The Legends of Khasak against the Malayalam text Khasakkinte Ithihasam to find out that Vijayan has taken great liberties in his rendering of the Malayalam novel into English. Raveendran opines that though the larger narrative is true to the original, the translation displays a drastic change in the sensibilities from the Malayalam text. Considering that Khasakkinte Ithihasam is hailed as the novel that brought in a new sensibility in Malayalam fiction and heralded in modernism, this is not a small alteration. Still, the question remains as to whether sensibility (rooted in specific time and space) can be translated from one language to another or from one culture to another, or will a particular sensibility of one time period be relevant in another, or more importantly is it imperative that sensibility gets translated? The original Khasak as was mentioned earlier was a new experience to Malayalis who were only fed on realistic novels till then. Thus it "challenged the dominant sensibility" of the day to offer something absolutely fresh and novel in material and method. Raveendran points out that there is a significant change in the worldview represented in the original and the translation. He also feels that the translation cannot be read as "a worldview transcending modernism, [a]s the articulation of a nativist, ecofeminist, communitarianist .... postmodern view" (2009: 131) as Vijayan's trajectory as a writer is not similar to that of the trend of Malayalam literature. Raveendran claims that while Malayalam literature went through a politicized modern phase to "find shelter under the rubric of postmodernism", Vijayan briefly went through a political phase to move ideologically closer to "versions of Indian metaphysics" (2009: 131). Vijayan translated Khasakkinte Ithihasam in this later phase, and Raveendran elaborates upon the implication of this on the translation:

Though there is a pronouncedly spiritual dimension to Khasakkinte Ithihasam too, the dialogically structured text of the novel does not allow a metaphysical reading to assert itself there. It is this 
possibility of a dialogic and compulsive misreading that has been denied to the text in the process of translation (2009: 131).

The Malayalam text offers itself to multiple readings from "social, political, sociological or even ecological terms" while in English, Khasak ends up being the metaphysical musings of a wandering soul. Raveendran highlights this by way of a simple example from the Malayalam and its corresponding translation. In their discussion about truth, the natives of Khasak who belong to different faiths, come up with the conclusion that "truth is varied" while the English translation says "Many truths make the big truth." The transition from "varied truths" to "the big truth" is what marks the original from the translation, according to Raveendran.

Khasakkinte Ithihasam is Vijayan's first novel and was published in 1969. But the translation came in 1994, when Vijayan had already written Gurusagaram (1987), Pravachakante Vazhi (1992) and Madhuram Gayathi (2007). All these novels are concerned in one way or the other with the metaphysical search of the oneness of God and The Legends of Khasak fits in perfectly within the fold of these works. The quest about the truth which he started with Gurusagaram continues through the tormented self of Ravi. But Vijayan's Ravi when he alighted from the bus at Koomankavu years before in 1969 was a cheerful young man though at times haunted by the ghosts of the past. He got burdened by the quest of truth only years later, in 1994, when Vijayan translated his Malayalam text into English. This progression from the text to the translated text can be substantiated through a close reading of the very first chapter of both the texts.

\section{The first chapter of The Legends: A close reading against the Malayalam text}

Ravi in Khasakkinte Ithihasam, reaches Koomankavu and stays in the bus for a short while even after the others started leaving, as he was feeling dizzy after the long winding bus journey and needed some rest before he started his walk towards his destination. It was as if he has reached a "dasa sandhi". This astrological term only means the lull in one's life after one phase and before the next one gathered momentum. It need not necessarily be astrologically considered bad for all people. But Vijayan in the translation makes it the "ominous transit in one's horoscope" (Vijayan 1994: 1), to make it feel that Ravi is indeed going to start a more difficult phase in his life. Thus the tonal variation of the two novels is set in the very first page of the translation itself. When the bus conductor gets someone to carry Ravi's luggage, he alights from the bus with a grateful 'thank you'. But in the translation, "Ravi stepped out of the bus, still wrapped in thought and the earth seemed to slip away from under his feet (Vijayan 1994: 1)". This seems like a loaded statement while in the Malayalam text Ravi was feeling dizzy because of the tiring journey. The Malayalam text says, "it was funny, it felt as if he was sticking 
his head out of a bus that was negotiating a narrow ghat path"2 (Vijayan 1969: 9). When he spots the shack selling sherbet, Ravi asks for two sherbets. When the porter protests that he doesn't want it, Ravi in good humoured camaraderie insists that he has it. He calls the porter "karnnore" which literally means "the elder one" but the term is used not in a sombre way as in the English text. The very line "Ravi encouraged him: Have it Karnnore. Isn't there quite a distance to tread from here?" (Vijayan 1969: 10), tells the readers that Ravi is a social being interested in engaging with people while the dialogues have been paraphrased in the English version not to interrupt the alienated reverie of Ravi: "The old man declined with peasant ceremony, but Ravi took him along anyway to the shack that sold sherbet" (Vijayan 1994: 2). He adds: "Ravi sat over another drink and desultorily scanned the knick-knackery in the shack" (2). In the Malayalam text Ravi only looks at the different things in the shop. Looking at the gramophone in the shop he feels an overwhelming mist of memories enfolding him. But in the English, Vijayan qualifies the memories: "mists of memory rose from its damp, rusted flues and spoke to Ravi in sad and tender voices" (Vijayan 1994: 3, my emphasis). In the Malayalam it is mentioned that within the time of having the sherbet, the shopkeeper extracted all the information from Ravi. He too takes part in the conversation: "Ravi elaborated. It is a single teacher school. A new experiment of the District board" (Vijayan 1969: 10). In the English version, Vijayan has added dialogues, but Ravi seems to be not too interested in the dialogue.

'Where might you be going?' asked the vendor.

'Visiting relatives?'

'No. I'm going there to teach.'

'Teach? In Khasak? There isn't a school there, at least there wasn't till the other day ...'

'One of the District Board's new single teacher schools. I am supposed to get it started.' (Vijayan 1994: 3)

About his saffron dhoti, in the Malayalam text, Ravi says that he has the fever of philosophy while in the English, Ravi somberly tells the shopkeeper that the dhoti is from an ashram, which complements his air of alienation. Vijayan even gives the old porter a philosophical line in the English text: "Loads are loads always" (Vijayan 1994: 3). Here Ravi offers to help the porter though he does not actually do that. This bit of conversation is not in the Malayalam text. The original Ravi seems to be very much a part of the feudal set up of India and does not mind the elderly man carrying his load. When Ravi pauses on the way to look at the bus going back the old man asks Ravi whether he is tired. He further asks him: "You were lost in some thought, weren't you?" (Vijayan 1969: 13), while the translation says: "Something made you sad?" (Vijayan 1994: 5), thus imposing the possibility

\footnotetext{
${ }^{2}$ All alternative translations are mine.
} 
of sadness on Ravi. On their long walk to Khasak from Koomankavu, the elderly man keeps on talking. While talking about the rain and its vagaries, the man asks Ravi: "Isn't it Maya, kutty?" The Malayalam says Ravi had an urge to display some philosophical skill, but decided not to because "he was tired. He just wanted to reach his destination somehow" (Vijayan 1969: 13). The English version reads as the following: "For a moment he had a frivolous impulse to play the mystic; he smothered it. No, not on this journey of many lives, this journey of incredible burdens. Let me reach my inn, the village called Khasak" (Vijayan 1994: 6). In the Malayalam text, the old man talks against the dam which is being built, while Ravi supports it: "One needn't be so anxious about the rains then." Vijayan writes: "the ease of the conversation snapped" (Vijayan 1969: 13). But Ravi regrets it and feels that he shouldn't have said that. In the translation this part is deleted so that Ravi seems to be a disinterested listener to the old man's chatter. When they reach Khasak, Ravi first just takes in the scene. But in the English version, Vijayan underlines the purpose of Ravi's visit with the thought: “... so this is my transit residency, my sarai" (Vijayan 1994: 7).

Once Sivaraman Nair, the landlord, leaves Ravi alone, the children and women throng to see the new teacher. "The children spoke in chorus, like so many anklets; these silver voices were soon to soothe his sorrow" (Vijayan 1994: 8). This "sorrow" is completely absent in Malayalam. There he is "so tired and a little annoyed with the children that after a while tell them firmly that they should leave" (Vijayan 1969: 15). Later when he sits down to rest "[His] calves hurt, his bones ached, the pain travelled through them, travelled dully through his mind..." (Vijayan 1994: 9). In the Malayalam, Ravi experiences only body ache! When he goes to the river after his sleep, Ravi finds two women bathing, half naked. In the Malayalam, "Ravi remains neck deep in water desultorily looking at them. When they left wrapping their sari around them, Ravi became alone" (Vijayan 1969: 15, my emphasis). In the English version, Ravi never even felt the company of women; rather he sits alone on the riverbed.

These examples from the very first chapter make one thing clear: that the protagonists of the Malayalam source text and the English translation are very different in spirit. The Ravi of Vijayan's Malayalam novel is an interesting young man who has come away to a village from an urban setting. He has good social skills and strikes up a conversation with the shack owner, the old porter and the children. He is a youngster full of life, very easily drawn to the opposite sex: he is quick to observe the women who came over to his house in the pretence of fetching their children; he is comfortable stepping into the river with the women bathing close by. Though Koomankavu seems vaguely familiar, he never betrays any belief in a predestined sarai. Rather, he is not even aware that he is on a painful journey of burden. Only Vijayan knows this as he rewrites the novel and he feels obliged to display it in no uncertain way, years later in the translation, that Ravi is an unhappy man. Thus the very first chapters of the original and the translation sketch two different portraits of the 
same character, Ravi: one a spirited young man, seemingly carefree and the other a melancholic who carries the burden of his life.

Apart from the changes in the protagonists' response to the world outside, there is a palpable change in the landscape of the novel as well. The Malayalam language in the novel has an intimate quality about it to match the warmth of its protagonist. In the first chapter, when Ravi reaches the school he observers the scene with delight to identify some birds that are common in rural Kerala. He takes in the greenery, the sight and sound (a mother calling out first Khadeeja, and then the more endearing Khadeejo) of the country-side which evoke a kind of familiarity in the Malayalam reader. This personalisation is missing in the English version.

More importantly, the first chapter of the translated text also makes one wonder whether Vijayan was writing exclusively for his international readers. Many details added in the narrative would give one the feel that Vijayan was interpreting or even adapting his text for a foreign audience. For example, in the shack where Ravi drinks his sherbet, he observes "gothic" lemonade bottles with deep green irises (Vijayan 1994: 2). In the Malayalam, the reference is to "lemonade bottles with irises" (Vijayan 1969: 10). Another addition is the mention of the "plantation's infirmary" and the nurses "who held him back" when his dead mother's strange "palanquin" was taken away. This can only be interpreted as an attempt to recreate a colonial atmosphere which the English readers might be familiar with. Most of the coffee plantations belonged to the British and a small clinic or infirmary would be part of the colonial master's charity enterprise. As a translator, Vijayan seems to have been thinking more about facilitating his readers than being 'loyal' to the original text. Thus from an analysis of the very first chapter we can conclude that the literary landscape of Khasak does undergo a mutation in translation as a result of the ideological shifts of the author and the translator's interpretative interventions to such an extent that Vijayan ended up rewriting his original by way of translation.

\section{Conclusion}

An ideal translator is one who has proficiency in two languages, and has knowledge of two cultures. Just as the original text is a result of controlled subjectivity, the translator is bound to bring in his own subjectivity in the interpretation of a text. According to Barthes while "a text consists of multiple writings issuing from several cultures and entering into dialogue with each other, into parody, into contestation" (2006: 6), all this gets unified in the reader. Thus the role of the translator is that of a reader and an author. Just as an author's work will have the collective pastness of her culture and her own personal past and present which come together in her in a particular intensity to result in a creative work, all these factors will determine the interpretation of the reading of a text by a translator which she in turn tries to recreate in a different culture and context, the effectiveness of which will be determined by the interpretation of another reader who might be far removed 164 
from the original text and culture. A translator does not exist in vacuum; she is very much a product of her own context. This is all the more true in selftranslation. It is also "a reminder that no act of interpretation can be definitive" (Venuti 1998: 46). Self-translation more often than not becomes rewriting, but an understanding of the thought processes and the evolution of the writer adds to the appreciation of the translation as an independent text in another language. Self-translation thus becomes the translation of the 'self' into a different context.

\section{References}

ARANDA, LuCÍA V. 2009. Forms of Creativity in Translation. Cadernos de Tradução, Brasil Florianópolis 1 .

ASADUDDIN M. 2008. Lost/Found in Translation: Qurratulain Hyder as Selftranslator. Annual of Urdu Studies 23. 234-49.

BASSNETT, SUSAN. 2013. The Self Translator as Rewriter. In Anthony Cordingley (ed.), Self Translation: Brokering Originality in Hybrid Culture. 13-26. New York and London: Bloomsbury Academic.

Butler, LANCE St. JoHN. 1994. A Solution to the Problem of Beckett's Bilingualism. Samuel Beckett Today / Aujourd'hui 3. Intertexts in Beckett's Work /Intertextes de I' oeuvre de Beckett. 115-135. JSTOR. Online: http://www.jstor.org/stable/41337856.

MuKherJeE, SuJIT. 2009. Translation as Recovery. New Delhi: Pencraft International.

RAVEENDRAN, P. P. 2009. Mapping the Khasak Landscape: An Essay on Translation. Texts Histories Geographies: Reading Indian Literature. New Delhi: Orient Blackswan.

SARANG, VILAS. 1981. Self translators. Journal of South Asian Literature. 16(2). Miscellany. 33-39. Jstor.

SATCHIDANANDAN, K. 2013. A Sage and an Iconoclast. Frontline 22(8). Online: www.frontline.in/static/html/fl2208/stories/ 20050422003113200. htm.

VENUTI, LAWRENCE. 1998. The Scandals of Translation: Towards an Ethics of Difference. London and New York: Routledge.

VIJAYAN, O. V. 1969. Khasakkinte Ithihasam. Reprint. Kottayam: DC Books. VIJAYAN, O. V. 1994. The Legends of Khasak. New Delhi: Penguin Books. 